\title{
Protocolo para Observação do Desenvolvimento Cognitivo e de Linguagem Expressiva - versão revisada (PODCLE-r): proposta de complementação
}

\section{Protocol for Expressive Language and Cognition Development Observation - revised version (PELCDO-r): complementation proposal}

\author{
Fabiola Custódio Flabiano', Karina Elena Bernardis Bühler², \\ Suelly Cecilia Olivan Limongi ${ }^{3}$, Debora Maria Befi-Lopes ${ }^{4}$
}

\begin{abstract}
RESUMO
Objetivo: Proposição de complementação do Protocolo para Observação do Desenvolvimento Cognitivo e de Linguagem Expressiva (PODCLE), a partir da inclusão de dois quadros que permitem a análise da diversidade das realizações e produções apresentadas pela criança e um quadro com a síntese das produções relacionadas à linguagem expressiva, organizadas em conjuntos. Métodos: Para a formalização de tal complementação, foram selecionados os indicadores mais significativos em relação ao desenvolvimento cognitivo e de linguagem expressiva, para os quais havia possibilidade de respostas diversificadas. Foi então desenvolvida uma escala de valores e pesos, de acordo com a complexidade das realizações e produções observadas em crianças. O Protocolo, em sua versão revisada, foi aplicado em diferentes populações para verificação de sua viabilidade e levantamento de possíveis dúvidas ou dificuldades durante sua aplicação ou análise dos dados. Juízes foram utilizados tanto para a seleção dos indicadores de desenvolvimento, quanto para a análise dos dados. Resultados: O Protocolo para Observação do Desenvolvimento Cognitivo e de Linguagem Expressiva - versão revisada (PODCLE-r) é composto por sete quadros, contendo os indicadores de desenvolvimento cognitivo e de linguagem expressiva durante o período sensório-motor e início do pré-operatório, que permitem a realização de duas formas de análise: macro e micro. Conclusão: O PODCLE-r permite ao examinador aprofundar seu olhar quanto ao desenvolvimento cognitivo e de linguagem expressiva da criança, considerando não apenas a presença ou ausência de determinado indicador, mas também a qualidade e diversidade de suas realizações e produções.
\end{abstract}

Descritores: Cognição; Desenvolvimento da linguagem; Protocolos

\section{INTRODUÇÃO}

Ao se trabalhar na proposição de protocolos de avaliação ou de observação de comportamentos, um problema enfren-

Trabalho realizado no Departamento de Fisioterapia, Fonoaudiologia e Terapia Ocupacional da Faculdade de Medicina da Universidade de São Paulo - USP - São Paulo (SP), Brasil, como parte de pesquisa financiada pela Fundação de Amparo à Pesquisa do Estado de São Paulo - FAPESP, em forma de Auxílio à Pesquisa.

(1) Pesquisadora do Laboratório de Investigação Fonoaudiológica em Síndromes e Alterações Sensório-Motoras da Faculdade de Medicina da Universidade de São Paulo - USP - São Paulo (SP), Brasil; Pós-graduanda do Programa de Pós-Graduação em Ciências da Reabilitação da Faculdade de Medicina da Universidade de São Paulo - USP - São Paulo (SP), Brasil.

(2) Doutora, Fonoaudióloga do Hospital Universitário da Universidade de São Paulo - HU-USP - São Paulo (SP), Brasil.

(3) Livre-Docente, Professora do Curso de Fonoaudiologia da Faculdade de Medicina da Universidade de São Paulo - USP - São Paulo (SP), Brasil.

(4) Livre-Docente, Professora do Curso de Fonoaudiologia da Faculdade de Medicina da Universidade de São Paulo - USP - São Paulo (SP), Brasil.

Endereço para correspondência: Suelly Cecília Olivan Limongi. R. Cipotânea, 51, Cidade Universitária, São Paulo - SP, CEP 05360-160. E-mail: slimongi@usp.br

Recebido em: 15/7/2008; Aceito em: 06/10/2008 tado trata da forma como estabelecer valores aos parâmetros a serem estudados.

A proposição de um instrumento de avaliação e/ou observação, que caracterize de forma segura e fidedigna o desenvolvimento apresentado pelo sujeito, implica no estudo cuidadoso dos itens e subitens que o comporão, bem como dos valores a serem atribuídos de acordo com cada indicador de desenvolvimento observado, de forma que este permita a comparação de dados, considerando-se tanto aspectos gerais quanto aspectos específicos.

Nesse sentido, a análise qualitativa quantificada pode contribuir de forma importante para os estudos fonoaudiológicos, principalmente para aqueles relacionados ao desenvolvimento de fala e linguagem, mais ainda quando já está determinada a relação linguagem-cognição no processo de construção do conhecimento feito pelo sujeito. A referência é feita ao fato que a quantificação é importante para que os dados possam ser comparados de forma objetiva. Assim, determina-se um valor numérico para um fenômeno, considerando-se seu aumento, estabilidade ou diminuição, sem desconsiderar a busca pelo aspecto sensível do fenômeno, isto é, o atributo exclusivo re- 
lacionado ao sujeito. Tal forma de análise torna possível, não só a localização do sujeito no percurso do desenvolvimento tido como geral e esperado, mas permite também analisar suas peculiaridades.

Citam-se alguns estudos que reforçam a importância em serem consideradas as evidências ao se caracterizar achados ${ }^{(1-4)}$. Tais estudos são unânimes em apontar que a sistematização de avaliações pelo uso de provas, que também permitam o estabelecimento de parâmetros quantitativos, fornece o controle objetivo e sistemático de tratamentos ou processos terapêuticos, uma vez que permite a comparação de dados entre avaliações iniciais e reavaliações. Considera-se, também, a oportunidade do estabelecimento de planos de trabalho com pacientes e suas adequações quando necessárias, após a identificação de possíveis inadequações, o que é mais facilmente observado com a comparação de resultados coletados e analisados sob a mesma metodologia, além do fato de poderem ser replicados em diferentes populações.

Alguns estudos ${ }^{(2-3,5-6)}$ propõem, especificamente, o estabelecimento de pontos a itens e subitens, no sentido de formação de uma escala de valores, justamente para favorecer a obtenção de escores e permitir a localização dos sujeitos estudados nessa escala e a comparação com grupos-controle ou outros grupos-pesquisa. Com a atenção voltada à especificidade da qualidade dos dados obtidos por esse meio de avaliação, autores $^{(5)}$ sugerem a utilização de escala de pesos para subitens. Essa seria uma forma de, complementando a análise mais geral e objetiva, obter a análise qualitativa mais específica, de maneira a valorizar as realizações e produções do indivíduo conforme sua complexidade e importância no processo de desenvolvimento.

O PODCLE, proposto em estudo anterior ${ }^{(7)}$, foi elaborado com base na literatura ${ }^{(8-14)} \mathrm{e}$ obedece à hierarquia do processo de construção, como propõem os referidos autores, considerando-se tanto a cognição quanto a linguagem expressiva.

A proposta para análise dos dados referentes às realizações e produções das crianças, apresentadas no PODCLE, permite a localização da criança em seu desenvolvimento cognitivo e de linguagem expressiva, como também o seu acompanhamento durante esses estágios iniciais. Porém, ela não se mostrou sensível a alguns aspectos qualitativos importantes para a observação desse processo de construção.

Portanto, o objetivo do presente estudo foi a proposição de complementação do Protocolo para Observação do Desenvolvimento Cognitivo e de Linguagem Expressiva (PODCLE), a partir da inclusão de dois quadros que permitem a análise da diversidade das realizações e produções apresentadas pela criança e um quadro-síntese que apresenta as produções relacionadas ao desenvolvimento da linguagem expressiva, organizadas em conjuntos.

A proposta de tal complementação justifica-se pela necessidade de considerar a diversidade das realizações e produções apresentadas por crianças ao longo do desenvolvimento cognitivo e de linguagem expressiva, caracterizando esse processo não apenas em termos da presença ou ausência de determinados indicadores de desenvolvimento, mas também quanto à evolução da qualidade e complexidade com que são apresentados.

\section{MÉTODOS}

Este estudo foi aprovado pelo Comitê de Ética em Pesquisa do Hospital Universitário da Universidade de São Paulo, sob protocolo n ${ }^{\circ}$ 592/05 e pela Comissão de Ética para Análise de Projetos de Pesquisa CAPPesq da Diretoria Clínica do Hospital das Clínicas e da Faculdade de Medicina da Universidade de São Paulo, sob protocolos nos 397/05 e 082/07.

Para a formalização da complementação do PODCLE, foram verificados todos os indicadores em relação ao desenvolvimento cognitivo e de linguagem expressiva, para os quais havia possibilidade de respostas diversificadas. Destes, foram selecionados aqueles que evidenciavam, de forma mais direta, a qualidade das realizações e produções apresentadas pelas crianças. Para tanto, foram utilizados dois juízes, fonoaudiólogas, uma doutora e outra doutoranda com experiência na área de desenvolvimento cognitivo e de linguagem. Foram considerados para a composição dos dois quadros de análise apresentados no presente estudo, os indicadores de desenvolvimento para os quais a concordância foi superior a $80 \%$.

Foi então desenvolvida uma escala de valores e pesos, de acordo com a complexidade das realizações e produções observadas em crianças, para os indicadores de desenvolvimento selecionados. Um estatístico foi consultado com vistas a garantir que a atribuição dos pesos fosse realizada de forma adequada e coerente e que permitisse o tratamento estatístico.

Em função da nova configuração do Protocolo, em sua versão revisada, são propostas duas formas complementares de análise, denominadas análise macro e análise micro.

A análise macro refere-se à verificação da presença ou ausência de determinado indicador de desenvolvimento, no momento da aplicação do Protocolo, permitindo localizar a criança em seu processo de desenvolvimento cognitivo e de linguagem expressiva.

A análise micro, por sua vez, refere-se à verificação da diversidade das realizações e produções apresentadas pela criança, possibilitando a caracterização do sujeito quanto à qualidade de seu desenvolvimento.

Para a verificação de sua viabilidade e levantamento de possíveis dúvidas ou dificuldades durante sua aplicação ou análise dos dados em diferentes populações, o Protocolo para Observação do Desenvolvimento Cognitivo e de Linguagem Expressiva - versão revisada (PODCLE-r) foi aplicado, como estudo piloto ${ }^{(15)} \mathrm{em}$ cinco crianças com desenvolvimento típico, que freqüentavam a creche do Hospital Universitário da USP, cinco crianças nascidas pré-termo muito baixo peso, que frequentavam o ambulatório de alto-risco do Hospital Universitário e cinco crianças com síndrome de Down, que frequentavam o Laboratório de Investigação Fonoaudiológica em Síndromes e Alterações Sensório-Motoras da USP (LIFSASM), acompanhadas mensalmente durante dez meses.

Para análise de $20 \%$ das sessões de observação, foram utilizados os mesmos dois juízes que participaram da seleção dos indicadores de desenvolvimento que comporiam o presente Protocolo. O índice de concordância foi de $89 \%$ para o juiz 1 e de $94 \%$ para o juiz 2 . Tal procedimento foi realizado com o propósito de verificar a objetividade das duas formas complementares de análise (macro e micro) para a caracterização 
mais fidedigna do processo de desenvolvimento cognitivo e de linguagem expressiva dos grupos estudados, bem como o levantamento de possíveis dúvidas ou dificuldades durante sua aplicação.

As fonoaudiólogas-juízes relataram que a análise micro, apesar de mais trabalhosa do que a análise macro, devido à análise da diversidade das produções e realizações apresentadas pela criança e aos cálculos numéricos mais complexos em função dos pesos atribuídos, permitiu diferenciar, de forma mais precisa e específica, os grupos de sujeitos estudados, complementando a análise macro de maneira efetiva. A integração da análise micro ao Protocolo levou a um acréscimo de 20 a 40 minutos no tempo necessário para análise dos dados, dependendo da idade da criança.

\section{RESULTADOS}

Como resultado, propõe-se o Protocolo para Observação do Desenvolvimento Cognitivo e de Linguagem Expressiva versão revisada (Anexo 1, Quadros 1-7) referente ao período sensório-motor e início do pré-operatório.

O PODCLE-r é composto de uma folha para descrição das observações em relação ao desempenho da criança (Anexo 1), cinco quadros referentes à pontuação e pesos correspondentes para a realização das análises macro e micro (Quadros 1-3, 6-7) e dois quadros-sínteses que permitem a localização da criança em seu desenvolvimento cognitivo e de linguagem expressiva (Quadros 4 e 5).

O Quadro 1 refere-se à atribuição de pontos de acordo com as realizações da criança em relação aos indicadores de desenvolvimento cognitivo durante o período sensório-motor e início do pré-operatório (análise macro).

O Quadro 2 refere-se à atribuição de pontos de acordo com as produções apresentadas em relação aos indicadores do desenvolvimento de linguagem expressiva durante o período sensório-motor e início do pré-operatório (análise macro).

Os indicadores que compõem os Quadros 1 e 2, bem como os procedimentos para sua verificação, estão descritos em estudo anterior ${ }^{(7)}$.

O Quadro 3 apresenta a pontuação obtida para cada um dos indicadores do desenvolvimento cognitivo e de linguagem expressiva, cuja soma indicará o valor que deverá ser utilizado para a localização da criança em seu desenvolvimento (análise macro), conforme os Quadros 4 e 5.

O Quadro 4 apresenta a síntese das realizações que caracterizam o desenvolvimento cognitivo relacionadas aos estágios do período sensório-motor e início do pré-operatório (análise macro).

O Quadro 5 apresenta a síntese das produções que caracterizam o desenvolvimento da linguagem expressiva, organizadas em conjuntos (análise macro).

O Quadro 6 refere-se à atribuição de pontos e pesos de acordo com a diversidade de realizações da criança em relação aos indicadores de desenvolvimento cognitivo durante o período sensório-motor e início do pré-operatório (análise micro). Os indicadores que compõem o Quadro 6, bem como os procedimentos para o cálculo da pontuação, de acordo com os pesos estabelecidos, são apresentados a seguir:

1. Imitação de esquemas motores: deve ser anotado o número de esquemas motores diferentes realizados pela criança, na presença do modelo, durante a sessão de observação, nos espaços reservados correspondentes às seguintes categorias:

a) esquemas isolados visíveis no próprio corpo (Exemplos: bater palmas, dar tchau, apontar, movimentar o dedo indicador em sinal de "não" etc.).

b) esquemas isolados não visíveis no próprio corpo (Exemplos: mandar beijo com estalos de lábios e realizar vibração de lábios ou estalos de língua etc.).

Quadro 1. Protocolo de pontuação da cognição

\begin{tabular}{|c|c|c|c|c|c|}
\hline \multicolumn{6}{|c|}{ Pontuação (análise macro) } \\
\hline \multirow{2}{*}{$\begin{array}{l}\text { Indicadores do } \\
\text { desenvolvimento } \\
\text { cognitivo }\end{array}$} & \multicolumn{5}{|c|}{ Realizações da criança } \\
\hline & 0 & 1 & 2 & 3 & 4 \\
\hline $\begin{array}{l}\text { Aplicação de esquemas } \\
\text { sensório-motores }\end{array}$ & não realiza & $\begin{array}{c}\text { aplicação de } \\
\text { esquemas isolados }\end{array}$ & $\begin{array}{l}\text { aplicação de } \\
\text { esquemas } \\
\text { coordenados }\end{array}$ & & \\
\hline $\begin{array}{l}\text { Deslocamento dos } \\
\text { objetos no espaço }\end{array}$ & não realiza & $\begin{array}{l}\text { acompanha de } \\
\text { forma incompleta }\end{array}$ & $\begin{array}{l}\text { acompanha de } \\
\text { forma completa }\end{array}$ & & \\
\hline Permanência do objeto & não realiza & $\begin{array}{l}\text { procura pelo objeto } \\
\text { parcialmente } \\
\text { escondido }\end{array}$ & $\begin{array}{l}\text { procura pelo } \\
\text { objeto totalmente } \\
\text { escondido }\end{array}$ & $\begin{array}{c}\text { realiza considerando } \\
\text { deslocamentos } \\
\text { visíveis }\end{array}$ & $\begin{array}{c}\text { realiza considerando } \\
\text { deslocamentos } \\
\text { invisíveis }\end{array}$ \\
\hline $\begin{array}{l}\text { Imitação de esquemas } \\
\text { motores (com o modelo) }\end{array}$ & não realiza & $\begin{array}{c}\text { esquemas isolados } \\
\text { visíveis no próprio } \\
\text { corpo } \\
\end{array}$ & $\begin{array}{l}\text { esquemas isolados } \\
\text { não visíveis no } \\
\text { próprio corpo } \\
\end{array}$ & $\begin{array}{c}\text { esquemas que } \\
\text { designam função aos } \\
\text { objetos }\end{array}$ & \\
\hline $\begin{array}{l}\text { Experiências com } \\
\text { objetos novos }\end{array}$ & não realiza & & realiza & & \\
\hline Uso de objeto como meio & não realiza & conduta do suporte & conduta do barbante & conduta da vara & \\
\hline $\begin{array}{l}\text { Uso de esquemas } \\
\text { simbólicos simples } \\
\text { (sem o modelo) }\end{array}$ & não realiza & $\begin{array}{l}\text { aplica no próprio } \\
\text { corpo }\end{array}$ & $\begin{array}{l}\text { aplica em objetos } \\
\text { figurativos }\end{array}$ & $\begin{array}{l}\text { aplica em objetos não } \\
\text { figurativos }\end{array}$ & \\
\hline $\begin{array}{c}\text { Uso de esquemas } \\
\text { simbólicos combinados } \\
\text { (sem o modelo) }\end{array}$ & não realiza & $\begin{array}{l}\text { combina duas } \\
\text { ações }\end{array}$ & $\begin{array}{l}\text { combina três ou } \\
\text { mais ações não } \\
\text { ordenadas }\end{array}$ & $\begin{array}{l}\text { combina três } \\
\text { ou mais ações } \\
\text { ordenadas }\end{array}$ & \\
\hline
\end{tabular}


Quadro 2. Protocolo de pontuação da linguagem expressiva

\begin{tabular}{|c|c|c|c|c|c|c|c|}
\hline \multicolumn{8}{|c|}{ Pontuação (análise macro) } \\
\hline \multirow{2}{*}{$\begin{array}{l}\text { Indicadores do } \\
\text { desenvolvimento } \\
\text { de linguagem } \\
\text { expressiva }\end{array}$} & \multicolumn{7}{|c|}{ Produções da criança } \\
\hline & 0 & 1 & 2 & 3 & 4 & 5 & 6 \\
\hline $\begin{array}{l}\text { Uso de gestos } \\
\text { dêiticos }\end{array}$ & não realiza & $\begin{array}{c}\text { por imitação } \\
\text { simples (com o } \\
\text { modelo) }\end{array}$ & $\begin{array}{c}\text { por imitação } \\
\text { simples } \\
\text { acompanhados } \\
\text { de } \\
\text { vocalizações }\end{array}$ & $\begin{array}{l}\text { por imitação } \\
\text { diferida (sem o } \\
\text { modelo) }\end{array}$ & $\begin{array}{c}\text { por imitação } \\
\text { diferida } \\
\text { acompanhados } \\
\text { de } \\
\text { vocalizações }\end{array}$ & & \\
\hline $\begin{array}{l}\text { Uso de gestos } \\
\text { representativos }\end{array}$ & não realiza & $\begin{array}{c}\text { por imitação } \\
\text { simples (com o } \\
\text { modelo) }\end{array}$ & $\begin{array}{c}\text { por imitação } \\
\text { simples } \\
\text { acompanhados } \\
\text { de } \\
\text { vocalizações }\end{array}$ & $\begin{array}{l}\text { por imitação } \\
\text { diferida (sem } \\
\text { o modelo) ou } \\
\text { representação } \\
\text { simbólica }\end{array}$ & $\begin{array}{l}\text { por imitação } \\
\text { diferida ou } \\
\text { representação } \\
\text { simbólica, } \\
\text { acompanhados } \\
\text { de } \\
\text { vocalizações }\end{array}$ & $\begin{array}{c}\text { por imitação } \\
\text { diferida, } \\
\text { acompanhados } \\
\text { de sílabas com } \\
\text { significado ou } \\
\text { onomatopéias } \\
\text { vocais }\end{array}$ & \\
\hline $\begin{array}{l}\text { Produção de } \\
\text { verbalizações } \\
\text { acompanhadas } \\
\text { por gestos } \\
\end{array}$ & não realiza & $\begin{array}{l}\text { sílabas com } \\
\text { significado }\end{array}$ & $\begin{array}{c}\text { palavras } \\
\text { monossilábicas } \\
\text { e/ou } \\
\text { interjeições } \\
\end{array}$ & $\begin{array}{c}\text { palavras } \\
\text { onomatopaicas }\end{array}$ & $\begin{array}{c}\text { palavras } \\
\text { isoladas com } \\
\text { mais de uma } \\
\text { sílaba } \\
\end{array}$ & $\begin{array}{c}\text { combinação } \\
\text { de duas } \\
\text { palavras }\end{array}$ & $\begin{array}{c}\text { combinação de } \\
\text { mais de duas } \\
\text { palavras }\end{array}$ \\
\hline $\begin{array}{l}\text { Produção de } \\
\text { verbalizações } \\
\text { isoladas }\end{array}$ & não realiza & $\begin{array}{l}\text { sílabas com } \\
\text { significado } \\
\text { relacionadas } \\
\text { ao contexto ou } \\
\text { objeto }\end{array}$ & $\begin{array}{c}\text { palavras } \\
\text { monossilábicas } \\
\text { e/ou } \\
\text { interjeições }\end{array}$ & $\begin{array}{c}\text { palavras } \\
\text { onomatopaicas }\end{array}$ & $\begin{array}{c}\text { palavras } \\
\text { isoladas com } \\
\text { mais de uma } \\
\text { sílaba }\end{array}$ & $\begin{array}{c}\text { combinação } \\
\text { de duas } \\
\text { palavras }\end{array}$ & $\begin{array}{c}\text { combinação de } \\
\text { mais de duas } \\
\text { palavras }\end{array}$ \\
\hline
\end{tabular}

Quadro 3. Protocolo de pontuação da cognição e da linguagem expressiva (análise macro)

\begin{tabular}{|c|c|c|c|}
\hline Cognição & Pontuação & Linguagem expressiva & Pontuação \\
\hline $\begin{array}{c}\text { Aplicação de esquemas sensório- } \\
\text { motores }\end{array}$ & & Uso de gestos dêiticos & \\
\hline Deslocamento dos objetos no espaço & & $\begin{array}{c}\text { Produção de verbalizações } \\
\text { acompanhadas por gestos }\end{array}$ & \\
\hline Permanência do objeto & Produção de verbalizações isoladas & \\
\hline $\begin{array}{c}\text { Imitação de esquemas motores (com o } \\
\text { modelo) }\end{array}$ & & & \\
\hline $\begin{array}{c}\text { Experiências com objetos novos } \\
\text { Uso de objetos como meio }\end{array}$ & & & \\
\hline $\begin{array}{c}\text { Uso de esquemas simbólicos simples } \\
\text { (sem o modelo) }\end{array}$ & & & \\
\hline $\begin{array}{c}\text { Uso de esquemas simbólicos } \\
\text { combinados (sem o modelo) }\end{array}$ & & & \\
\hline Total & & & \\
\hline
\end{tabular}

c) esquemas que designam funções aos objetos (Exemplos: levar o telefone à orelha, empurrar o carrinho, levar a colher à boca da boneca etc.).

2. Uso de esquemas simbólicos simples: deve ser anotado o número de esquemas simbólicos diferentes realizados pela criança, na ausência do modelo, durante a sessão de observação, nos espaços reservados correspondentes às seguintes categorias:

a) aplicação no próprio corpo (exemplos: bater palmas, dar tchau, apontar, levar o telefone à própria orelha, levar a colher à própria boca etc.).

b) aplicação em objetos figurativos (exemplos: empurrar o carrinho, levar o telefone à orelha da boneca, levar o copo à boca da boneca etc.).

c) aplicação em objetos não figurativos (exemplos: levar o chocalho à orelha, utilizando-o como telefone, esfregar uma peça de encaixe na barriga da boneca, utilizando-a como sabonete etc.).

3. Uso de esquemas simbólicos combinados: deve ser anotado o número de combinações diferentes de esquemas simbólicos realizados pela criança, na ausência do modelo, durante a sessão de observação, nos espaços reservados correspondentes às seguintes categorias:

a) combinação de duas ações (exemplos: apertar as teclas 
Quadro 4. Quadro de referência para as fases do desenvolvimento cognitivo (período sensório motor e início do pré-operatório)

\begin{tabular}{|l|l|l|}
\hline Pontuação & Realizações & Fase do desenvolvimento cognitivo \\
\hline 0 a 3 pontos & $\begin{array}{l}\text { Uso de esquemas isolados e acompanhamento do deslocamento do } \\
\text { objeto no espaço }\end{array}$ & $1^{\text {a }}$ e $2^{\text {a }}$. fases do período sensório-motor \\
\hline 3,1 a 6 pontos & $\begin{array}{l}\text { Uso de esquemas coordenados, procura pelo objeto parcialmente } \\
\text { escondido, imitação de esquemas visíveis no próprio corpo }\end{array}$ & $3^{\text {a }}$. fase do período sensório-motor \\
\hline 6,1 a 10 pontos & $\begin{array}{l}\text { Procura pelo objeto totalmente escondido, mas sem considerar seus } \\
\text { deslocamentos, imitação de esquemas não visíveis no próprio corpo, } \\
\text { condutas do suporte e do barbante }\end{array}$ & $4^{\text {a } \text {. fase do período sensório-motor }}$ \\
\hline 10,1 a 15 pontos & $\begin{array}{l}\text { Procura pelo objeto totalmente escondido, considerando apenas os } \\
\text { deslocamentos visíveis, imitação de esquemas coordenados, realiza } \\
\text { experiências com objetos novos e a conduta da vara }\end{array}$ & $5^{\text {a } \text {. fase do período sensório-motor }}$ \\
\hline 15,1 a 18 pontos & $\begin{array}{l}\text { Procura pelo objeto totalmente escondido, considerando os } \\
\text { deslocamentos visíveis e invisíveis, Uso de esquemas simbólicos } \\
\text { isolados, aplicados no próprio corpo ou em objetos figurativos }\end{array}$ & $6^{\text {a } \text {. fase do período sensório-motor }}$ \\
\hline 18,1 a 22 pontos & $\begin{array}{l}\text { Uso de esquemas simbólicos aplicados em material não figurativo, uso } \\
\text { de esquemas simbólicos combinados. }\end{array}$ & Início do período pré-operatório \\
\hline
\end{tabular}

Quadro 5. Quadro de referência para os indicadores do desenvolvimento de linguagem expressiva (período sensório-motor e início do préoperatório)

\begin{tabular}{|c|c|c|}
\hline Pontuação & Produções & Conjunto de produções \\
\hline 0 a 4 pontos & $\begin{array}{l}\text { Imitação de gestos dêiticos ou representativos, acompanhados ou não de } \\
\text { vocalizações }\end{array}$ & I \\
\hline 4,1 a 8 pontos & $\begin{array}{l}\text { Imitação diferida de gestos dêiticos ou representativos, acompanhados ou não de } \\
\text { vocalizações }\end{array}$ & II \\
\hline 8,1 a 13 pontos & $\begin{array}{l}\text { Imitação diferida de gestos representativos acompanhadas de onomatopéias } \\
\text { vocais ou sílabas com significado. Produção de sílabas com significado, palavras } \\
\text { monossilábicas e/ou interjeições acompanhadas ou não por gestos dêiticos ou } \\
\text { representativos }\end{array}$ & III \\
\hline 13,1 a 17 pontos & $\begin{array}{l}\text { Produção de palavras onomatopaicas e palavras com mais de uma sílaba, } \\
\text { acompanhadas ou não por gestos dêiticos ou representativos }\end{array}$ & IV \\
\hline 17,1 a 21 pontos & $\begin{array}{l}\text { Produção de combinações de duas ou mais palavras, acompanhadas ou não por } \\
\text { gestos dêiticos ou representativos }\end{array}$ & V \\
\hline
\end{tabular}

Quadro 6. Protocolo de pontuação da cognição (Análise micro)

\begin{tabular}{|c|c|c|c|c|}
\hline \multicolumn{5}{|c|}{ Pontuação (análise micro) } \\
\hline \multirow{2}{*}{$\begin{array}{c}\text { Indicadores de } \\
\text { desenvolvimento cognitivo }\end{array}$} & \multicolumn{4}{|c|}{ Realizações da criança } \\
\hline & Peso 1 & Peso 2 & Peso 3 & \\
\hline $\begin{array}{l}\text { Imitação de esquemas } \\
\text { motores (com o modelo) }\end{array}$ & $\begin{array}{c}\text { esquemas isolados } \\
\text { visíveis no próprio corpo }\end{array}$ & $\begin{array}{l}\text { esquemas isolados não } \\
\text { visíveis no próprio corpo }\end{array}$ & $\begin{array}{l}\text { esquemas que designam } \\
\text { função aos objetos }\end{array}$ & Total \\
\hline \multicolumn{5}{|l|}{ Diversidade (Peso 1) } \\
\hline $\begin{array}{l}\text { Uso de esquemas } \\
\text { simbólicos simples } \\
\text { (sem o modelo) }\end{array}$ & aplica no próprio corpo & $\begin{array}{l}\text { aplica em objetos } \\
\text { figurativos }\end{array}$ & $\begin{array}{c}\text { aplica em objetos não } \\
\text { figurativos }\end{array}$ & Total \\
\hline \multicolumn{5}{|l|}{ Diversidade (Peso 2) } \\
\hline $\begin{array}{c}\text { Uso de esquemas } \\
\text { simbólicos combinados } \\
\text { (sem o modelo) }\end{array}$ & combina duas ações & $\begin{array}{l}\text { combina três ou mais } \\
\text { ações não ordenadas }\end{array}$ & $\begin{array}{l}\text { combina três ou mais } \\
\text { ações ordenadas }\end{array}$ & Total \\
\hline Diversidade (Peso 3) & & & & \\
\hline & & & Total geral & \\
\hline
\end{tabular}


do telefone, levando-o à orelha em seguida; mexer com a colher dentro do pote, levando-a à boca em seguida, raspar a colher no prato, levando-a à boca da boneca em seguida etc.).

b) combinação de três ou mais ações não-ordenadas (exemplo: colocar a boneca na banheira, esfregar sua barriga e depois tirar sua roupa etc.).

c) combinação de três ou mais ações ordenadas (exemplo: raspar a colher no prato, levar a colher à boca da boneca, limpando a boca da boneca em seguida etc.).

Após a anotação do número de realizações diferentes apresentadas pela criança em relação às categorias de cada um dos indicadores do desenvolvimento cognitivo, estes devem ser multiplicados pelo valor correspondente à linha (que indica o nível de complexidade em relação aos indicadores de desenvolvimento) e multiplicado novamente pelo valor correspondente à coluna (que indica o nível de complexidade das categorias de um mesmo indicador de desenvolvimento).

Os totais parciais referentes à soma dos valores (número de realizações diferentes apresentadas pela criança) das categorias já multiplicados de acordo com os pesos atribuídos à sua linha e coluna, devem ser anotados na ultima célula da linha correspondente ao indicador de desenvolvimento ao qual pertencem.
O total geral referente à soma dos totais parciais deve ser anotado ao final da última coluna da direita, e corresponde ao desempenho da criança quanto à qualidade de suas realizações em relação ao desenvolvimento cognitivo.

Os cálculos acima descritos, usados para análise micro referente ao desenvolvimento cognitivo, estão exemplificados no Anexo 2.

O Quadro 7 refere-se à atribuição de pontos e pesos de acordo com a diversidade das produções da criança em relação aos indicadores de desenvolvimento da linguagem expressiva durante o período sensório-motor e início do pré-operatório (análise micro). Os indicadores que compõem o Quadro 7, bem como os procedimentos para o cálculo da pontuação de acordo com os pesos estabelecidos são apresentados a seguir:

1. Uso de gestos dêiticos: deve ser anotado o número de gestos dêiticos diferentes realizados pela criança, durante a sessão de observação, nos espaços reservados correspondentes às seguintes condições de produção:

a) por imitação simples (exemplos: apontar, estender o braço, virar as palmas das mãos para cima (cadê) etc.), na presença do modelo.

b) por imitação simples, acompanhados de vocalizações (exemplos: apontar acompanhado da vocalização "auoi", estender o braço, acompanhado da vocalização "dadai”,

Quadro 7. Protocolo de pontuação da linguagem expressiva (análise micro)

\begin{tabular}{|c|c|c|c|c|c|c|c|}
\hline \multicolumn{8}{|c|}{ Pontuação (análise micro) } \\
\hline \multirow{2}{*}{$\begin{array}{l}\text { Indicadores de } \\
\text { desenvolvimento } \\
\text { da linguagem } \\
\text { expressiva }\end{array}$} & \multicolumn{7}{|c|}{ Produções da criança } \\
\hline & Peso 1 & Peso 2 & Peso 3 & Peso 4 & Peso 5 & Peso 6 & \\
\hline $\begin{array}{c}\text { Só de gestos } \\
\text { dêiticos }\end{array}$ & $\begin{array}{l}\text { por imitação } \\
\text { simples }\end{array}$ & $\begin{array}{c}\text { por imitação } \\
\text { simples } \\
\text { acompanhados de } \\
\text { vocalizações }\end{array}$ & $\begin{array}{l}\text { por imitação } \\
\text { diferida }\end{array}$ & $\begin{array}{c}\text { por imitação } \\
\text { diferida } \\
\text { acompanhados de } \\
\text { vocalizações }\end{array}$ & & & Total \\
\hline \multicolumn{8}{|l|}{$\begin{array}{c}\text { Diversidade } \\
\text { (Peso 1) }\end{array}$} \\
\hline $\begin{array}{l}\text { Uso de gestos } \\
\text { representativos }\end{array}$ & $\begin{array}{l}\text { por imitação } \\
\text { simples }\end{array}$ & $\begin{array}{c}\text { por imitação } \\
\text { simples } \\
\text { acompanhados de } \\
\text { vocalizações }\end{array}$ & $\begin{array}{l}\text { por imitação } \\
\text { diferida ou } \\
\text { representação } \\
\text { simbólica }\end{array}$ & $\begin{array}{l}\text { por imitação } \\
\text { diferida ou } \\
\text { representação } \\
\text { simbólica, } \\
\text { acompanhados de } \\
\text { vocalizações }\end{array}$ & $\begin{array}{c}\text { por imitação } \\
\text { diferida, } \\
\text { acompanhados } \\
\text { de sílabas com } \\
\text { significado ou } \\
\text { onomatopéias } \\
\text { vocais }\end{array}$ & & Total \\
\hline \multicolumn{8}{|l|}{$\begin{array}{l}\text { Diversidade (Peso } \\
\text { 2) }\end{array}$} \\
\hline $\begin{array}{l}\text { Produção de } \\
\text { verbalizações } \\
\text { acompanhadas } \\
\text { por gestos }\end{array}$ & $\begin{array}{l}\text { sílabas com } \\
\text { significado }\end{array}$ & $\begin{array}{c}\text { palavras } \\
\text { monossilábicas e/ } \\
\text { ou interjeições }\end{array}$ & $\begin{array}{c}\text { palavras } \\
\text { onomatopaicas }\end{array}$ & $\begin{array}{c}\text { palavras isoladas } \\
\text { com mais de uma } \\
\text { sílaba }\end{array}$ & $\begin{array}{l}\text { combinação de } \\
\text { duas palavras }\end{array}$ & $\begin{array}{c}\text { combinação de } \\
\text { mais de duas } \\
\text { palavras }\end{array}$ & Total \\
\hline \multicolumn{8}{|l|}{$\begin{array}{c}\text { Diversidade } \\
\text { (Peso 3) }\end{array}$} \\
\hline $\begin{array}{l}\text { Produção de } \\
\text { verbalizações } \\
\text { Isoladas }\end{array}$ & $\begin{array}{l}\text { sílabas com } \\
\text { significado }\end{array}$ & $\begin{array}{c}\text { palavras } \\
\text { monossilábicas e/ } \\
\text { ou interjeições }\end{array}$ & $\begin{array}{c}\text { palavras } \\
\text { onomatopaicas }\end{array}$ & $\begin{array}{c}\text { palavras isoladas } \\
\text { com mais de uma } \\
\text { sílaba }\end{array}$ & $\begin{array}{c}\text { combinação de } \\
\text { duas palavras }\end{array}$ & $\begin{array}{c}\text { combinação de } \\
\text { mais de duas } \\
\text { palavras }\end{array}$ & Total \\
\hline $\begin{array}{c}\text { Diversidade } \\
\text { (Peso 4) }\end{array}$ & & & & & & & \\
\hline & & & & & & Total geral & \\
\hline
\end{tabular}


virar as palmas das mãos para cima (cadê), acompanhado da vocalização "ababa" etc.), na presença do modelo.

c) por imitação diferida (exemplos: apontar, estender o braço, virar as palmas das mãos para cima (cadê) etc.), na ausência do modelo.

d) por imitação diferida acompanhado de vocalizações (exemplos: apontar acompanhado da vocalização "auoi", estender o braço, acompanhado da vocalização "dadai", virar as palmas das mãos para cima (cadê), acompanhado da vocalização "ababa" etc.), na ausência do modelo.

2. Uso de gestos representativos: deve ser anotado o número de gestos representativos diferentes realizados pela criança, durante a sessão de observação, nos espaços reservados correspondentes às seguintes condições de produção:

a) por imitação simples (exemplos: dar tchau, mandar beijo, levar o telefone à orelha, ninar a boneca em seus braços etc.), na presença do modelo.

b) por imitação simples, acompanhados de vocalizações (exemplos: dar tchau acompanhado da vocalização "aaaa", bater palmas acompanhadas da vocalização "eeeeeee", levar o telefone à orelha, acompanhado da vocalização "adaidaidai" etc.), na presença do modelo.

c) por imitação diferida (exemplos: dar tchau, mandar beijo, levar o telefone à orelha, ninar a boneca em seus braços etc.), na ausência do modelo.

d) por imitação diferida acompanhado de vocalizações (exemplos: dar tchau acompanhado da vocalização "aaaa", bater palmas, acompanhado da vocalização "eeeeeee", levar o telefone à orelha, acompanhado da vocalização "adaidaidai" etc.), na ausência do modelo.

e) por imitação diferida acompanhados por sílabas com significado ou onomatopéias vocais (exemplos: levar o telefone à orelha, acompanhado da sílaba com significado "lô" (alô); empurrar o carrinho, acompanhado de vibração de lábios (onomatopéia vocal), levar a colher à boca da boneca, realizando estalos de língua (onomatopéia vocal) etc.), na ausência do modelo.

3. Produção de verbalizações acompanhadas por gestos: deve ser anotado o número de verbalizações diferentes, acompanhadas por gestos realizados pela criança, durante a sessão de observação, nos espaços reservados correspondentes às seguintes categorias:

a) sílabas com significado (exemplos: "ô" (olha), acompanhada do gesto de apontar, "bô" (acabou), acompanhada do gesto de "acabou", virando as palmas das mãos para cima e abrindo os braços), relacionadas ao contexto ou objeto.

b) palavras monossilábicas elou interjeições (exemplos: "é", acompanhada do gesto representativo de balançar a cabeça em sinal de "sim"; "lá" acompanhada do gesto de apontar; "aô" (alô), acompanhada do gesto de levar o telefone à orelha, "tau" (tchau), acompanhada do gesto de dar tchau etc.). Diferenciam-se das sílabas com significado, acompanhadas por gestos dêiticos ou representativos, descritas no item a), por constituírem palavras monossilábicas ou interjeições, segundo a gramática da língua portuguesa.

c) palavras onomatopaicas (exemplos: "papá”, utilizado como substantivo acompanhado do gesto de apontar, "bibi" acompanhado do gesto de empurrar o carrinho). d) palavras isoladas com mais de uma sílaba (exemplos: "vovó" e "papai", acompanhadas do gesto de levar o telefone à orelha, "binquedo" (brinquedo) acompanhado do gesto dêitico de estender o braço, pedindo a sacola de brinquedos para a examinadora).

e) combinação de duas palavras (exemplos: "o oio" (o olho), ao apontar para o olho da boneca; "abô eti" (acabou o sabonete) acompanhado do gesto de acabou, etc.)

f) combinação de mais de duas palavras (exemplos: "qué vê essi" (quero ver esse), acompanhado do gesto de apontar para o objeto, "vô guadá o nenê" (vou guardar o nenê) etc.)

4. Produção de verbalizações isoladas: deve ser anotado o número de verbalizações diferentes realizadas pela criança, não acompanhadas por gestos, durante a sessão de observação, nos espaços reservados correspondentes às mesmas categorias descritas no item 3.

Após a anotação do número de realizações diferentes apresentadas pela criança em relação às categorias de cada um dos indicadores do desenvolvimento de linguagem expressiva, estes devem ser multiplicados pelos pesos de acordo com a linha e coluna às quais pertencem, seguindo os mesmos procedimentos de cálculo dos totais parciais e do total geral, descritos acima para a análise micro em relação ao desenvolvimento cognitivo.

Os cálculos para análise micro referente ao desenvolvimento da linguagem expressiva estão exemplificados no Anexo 3.

\section{Considerações sobre a aplicação do PODCLE-r}

A diversidade das realizações e produções da criança em relação aos indicadores referentes ao desenvolvimento cognitivo e de linguagem expressiva considerada, tanto para a análise macro quanto para a análise micro, deve ser verificada durante a aplicação do Protocolo. Portanto, não devem ser consideradas, para fins de análise dos dados, as informações trazidas pelos pais ou cuidadores a respeito do desenvolvimento cognitivo e de linguagem que não sejam verificadas durante a sessão de observação.

O PODCLE-r pode ser utilizado com os seguintes objetivos:

1) Localizar a criança em seu desenvolvimento cognitivo e de linguagem expressiva com relação aos estágios iniciais;

2) Acompanhar o desenvolvimento da criança longitudinalmente, ou seja, em diferentes momentos ao longo de seu processo de construção cognitiva e de linguagem expressiva, durante o período sensório-motor e início do pré-operatório.

No caso da observação longitudinal, os dados observados devem ser considerados como parte de um processo contínuo em que as aquisições são cumulativas. Assim, a pontuação referente tanto à análise macro quanto à análise micro, obtida em sessões anteriores, em que não haja dúvida do que foi observado, deverá ser mantida para a sessão seguinte, caso não seja possível observar determinado indicador novamente.

Especificamente em relação à análise micro, deverão ser consideradas e pontuadas somente as realizações e produções da criança que estão sendo observadas pela primeira vez em 
relação a cada indicador de desenvolvimento. Assim, se a criança apresentou, na primeira sessão de observação, a produção do gesto dêitico de apontar por imitação simples, este será pontuado uma única vez, independentemente do número de vezes em que for realizado pela criança, seja durante a mesma sessão, seja nas sessões seguintes. Porém, se o mesmo gesto dêitico de apontar for realizado em condição diferente (por imitação simples acompanhada de vocalizações, por imitação diferida ou por imitação diferida acompanhada de vocalizações) ele deverá ser pontuado novamente de acordo com a condição de realização. Em resumo, o mesmo esquema, gesto ou verbalização só poderá ser computado uma única vez em cada condição de realização prevista no Protocolo.

Em relação à produção de verbalizações, não devem ser considerados os erros fonológicos. Assim, se a criança, na primeira sessão de observação, apresentou a produção da palavra com mais de uma sílaba /ku'ع/ (colher) e em sessão posterior foi capaz de produzi-la de forma fonologicamente correta /ko' $\lambda \varepsilon R /$ (colher), isso não deve ser considerado para fins de análise, devendo esta produção ser computada uma unica vez, no momento em que foi observada pela primeira vez.

Outras considerações sobre a aplicação do presente protocolo estão descritas em estudo anterior ${ }^{(7)}$.

\section{DISCUSSÃO}

A proposta de complementação do Protocolo para Observação do Desenvolvimento Cognitivo e de Linguagem Expressiva $^{(7)}$, resultando em sua versão revisada (PODCLE-r), torna possível a caracterização do desenvolvimento do sujeito de forma mais minuciosa e específica, a partir da formalização das análises macro e micro. A análise macro nos fornecerá, por exemplo, que o sujeito foi capaz de utilizar esquemas que designam funções aos objetos e produzir palavras monossilábicas de forma isolada. A análise micro, por sua vez, complementará a análise macro, fornecendo informações quanto à diversidade das realizações e produções apresentadas pela criança, ou seja, quantos esquemas diferentes a criança foi capaz de realizar e quantas palavras monossilábicas diferentes foi capaz de produzir durante a sessão de observação ou ao longo de seu desenvolvimento. A análise micro permite, portanto, verificar como a cognição e a linguagem expressiva se desenvolvem em termos da qualidade das produções e realizações apresentadas pela criança.

A análise micro é também de grande utilidade na comparação inter-grupos, pois permite determinar diferenças qualitativas em relação ao desempenho dos sujeitos, mesmo que estes apresentem a mesma localização em relação ao desenvolvimento cognitivo e de linguagem expressiva, dada pela análise macro.

Nesse sentido, a proposição do PODCLE-r responde à necessidade apontada na literatura de utilização de instrumentos baseados em evidências científicas, que permitam a análise objetiva dos dados, fornecendo escores e parâmetros para maior controle e precisão em procedimentos de avaliação, diagnóstico e acompanhamento sistemático do processo terapêutico fonoaudiológico ${ }^{(1-2,16-19)}$.

\section{CONCLUSÃO}

O Protocolo para Observação do Desenvolvimento Cognitivo e de Linguagem Expressiva - versão revisada (PODCLEr), proposto no presente estudo, consiste em instrumento que permite ao profissional interessado aprofundar seu olhar quanto ao desenvolvimento cognitivo e de linguagem expressiva da criança durante o período sensório-motor e início do préoperatório, considerando não apenas a presença ou ausência de determinado indicador, mas também a qualidade e diversidade de suas realizações e produções. Tal Protocolo pode ser aplicado em diferentes populações e permite a comparação entre grupos pesquisa e controle, contribuindo assim, para a sistematização de estudos na área.

\section{AGRADECIMENTOS}

Agradecemos à Dra. Juliana Perina Gândara pelas importantes considerações, que contribuíram para a estruturação deste protocolo.

\begin{abstract}
Purpose: Proposition of complementation for the Protocol for Expressive Language and Cognitive Development Observation (PELCDO) by the inclusion of two tables that allow the analysis of child's productions and behaviors diversity, and one table with the synthesis of productions concerning expressive language, arranged in groups. Methods: For the systematization of such complementation, the most important indicators of expressive language and cognitive development that allow diversified answers were selected. Thus, based on the complexity of the behaviors and productions observed in young children, a scale of values and statistical weights was developed. The Protocol, in its revised version, was administered in different populations aiming to verify its applicability and to raise possible doubts or difficulties that may be noticed during its administration or data analysis. Judges were used for both selection of the indicators of expressive language and cognitive development and data analysis. Results: The Protocol for Expressive Language and Cognition Development Observation - revised version (PELCDO-r) is composed by seven tables, comprising the indicators of expressive language and cognitive development during sensorimotor and beginning of pre-operational periods, and it allows two forms of analysis: macro and micro. Conclusion: The PELCDO-r permits the enhancement of child development observation concerning expressive language and cognition, considering not only the presence or absence of some indicator of development, but also the diversity and quality of child's behaviors and productions.
\end{abstract}

Keywords: Cognition; Language development; Protocols 


\section{REFERÊNCIAS}

1. Andrade CRF, Juste F. Proposta de análise de performance e de evolução em crianças com gagueira desenvolvimental. Rev CEFAC. 2005;7(2):158-70.

2. Trindade IEK, Genaro KF, Yamashita RP, Miguel HC, Fukushiro AP. Proposta de classificação da função velofaríngea na avaliação perceptivo-auditiva da fala. Pró-Fono. 2005;17(2):259-62.

3. Manubens JM, Barandiarán M, Martinez-Lage P, Francés I, Martinez C, García ML, et al. Valores del protocolo neuropsicológico GERMCIDE en una muestra de sujetos normales. Neurologia. 2005;20(4):174-9.

4. McGivney GP. Evidence-based dentistry article series. J Prosthet Dent. 2000;83(1):11-2

5. Sato Y, Hamada S, Akagawa Y, Tsuga K. A method for quantifying overall satisfaction of complete denture patients. J Oral Rehabil. 2000;27(11):952-7.

6. Sato Y, Tsuga K, Akagawa Y, Tenma H. A method for quantifying complete denture quality. J Prosthet Dent. 1998;80(1):52-7.

7. Bühler KEB, Flabiano FC, Limongi SCO, Befi-Lopes DM. Protocolo para Observação do Desenvolvimento Cognitivo e de Linguagem Expressiva (PODCLE). Rev Soc Bras Fonoaudiol. 2008;13(1):60-8.

8. Piaget J. Construção do real na criança. Rio de Janeiro: Zahar Editora; 1970. [edição original 1937].

9. Piaget J. A formação do símbolo na criança: imitação, jogo e sonho, imagem e representação. 3a. ed. Rio de Janeiro: Zahar; 1978. [edição original 1946].

10. Piaget J. Nascimento da inteligência na criança. 3a ed. Rio de Janeiro: Zahar; 1978. [edição original 1936].

11. Bates E, Snyder L, Bretherton I, Volterra V. The emergency of symbols in language and action: similarities and differences. Papers and Reports on Child Development. 1979;17:106-18.

12. Bates E, Dick F. Language, gesture, and the developing brain. Dev Psychobiol. 2002;40(3):293-310.

13. Iverson JM, Longobardi E, Caselli MC. Relationship between gestures and words in children with Down's syndrome and typically developing children in the early stages of communicative development. Int J Lang Commun Disord. 2003;38(2):179-97.

14. Capone NC, McGregor KK. Gesture development: a review for clinical and research practices. J Speech Lang Hear Res. 2004;47(1):173-86.

15. Flabiano FC, Bühler KECB, Mendes AE, Limongi SCO. Quantitative and qualitative assessment of language and cognition in toddlers. In: American Speech-Language-Hearing Association - ASHA Convention, 2006. Miami. Miami Beach (FL): ASHA Convention; 2006.

16. Neiva FC, Wertzner HF. A protocol for oral myofunctional assessment: for application with children. Int J Orofacial Myology. 1996;22:8-19.

17. Andrade CRF, Befi-Lopes DM, Fernandes FDM, Wertzner HF, organizadores. ABFW: teste de linguagem infantil nas áreas de fonologia, vocabulário, fluência e pragmática. 2a ed. Barueri: Pró-Fono; 2004.

18. Giusti E. Performance de crianças falantes do português brasileiro no Test of Early Language Development (TELD-3) [tese]. São Paulo: Faculdade de Filosofia, Letras e Ciências Humanas da Universidade de São Paulo; 2007.

19. Padovani AR, Moraes DP, Mangili LD, Andrade CRF. Protocolo fonoaudiológico de avaliação do risco para disfagia (PARD). Rev Soc Bras Fonoaudiol. 2007;12(3):199-205.

Anexo 1. Folha de registro das observações (PODCLE-r)

\section{Observação $n^{\circ}$}

Nome:

D.N.

Data:

Idade:

\section{Cognição}

1. Aplicação de esquemas sensório-motores isolados e coordenados:

\section{Deslocamento dos objetos no espaço:}

\section{Permanência do objeto:}

4. Imitação de esquemas motores (com o modelo):

a. imitação de esquemas isolados visíveis no próprio corpo:

b. imitação de esquemas isolados não visíveis no próprio corpo:

c. imitação de esquemas que designam função aos objetos:

5. Experiências com objetos novos:

6. Uso de objetos como meios:
7. Uso de esquemas simbólicos simples (sem o modelo):

a. aplicação no próprio corpo:

b. aplicação em objetos figurativos:

c. aplicação em objetos não figurativos:

8. Uso de esquemas simbólicos combinados

a. combinação de 2 ações:

b. combinação de 3 ou mais ações não ordenadas:

c. combinação de 3 ou mais ações ordenadas:

\section{Linguagem Expressiva}

1. Uso de gestos dêiticos:

2. Uso de gestos representativos:

3. Produção de verbalizações acompanhadas por gestos:

4. Produção de verbalizações isoladas: 
Anexo 2. Exemplo do cálculo que deve ser realizado para análise micro referente ao desenvolvimento cognitivo

\begin{tabular}{|c|c|c|c|c|}
\hline \multicolumn{5}{|c|}{ Pontuação (análise micro) } \\
\hline \multirow{2}{*}{$\begin{array}{l}\text { Indicadores de } \\
\text { desenvolvimento } \\
\text { cognitivo }\end{array}$} & \multicolumn{4}{|c|}{ Realizações da criança } \\
\hline & Peso 1 & Peso 2 & Peso 3 & \\
\hline $\begin{array}{l}\text { Imitação de esquemas } \\
\text { motores (com o modelo) }\end{array}$ & $\begin{array}{l}\text { esquemas isolados } \\
\text { visíveis no próprio corpo }\end{array}$ & $\begin{array}{l}\text { esquemas isolados não } \\
\text { visíveis no próprio corpo }\end{array}$ & $\begin{array}{l}\text { esquemas que designam } \\
\text { função aos objetos }\end{array}$ & Total \\
\hline Diversidade (Peso 1) & $2(x 1 \times 1)=2$ & $1(x 1 \times 2)=2$ & $1(x 1 \times 3)=3$ & $7(2+2+3)$ \\
\hline $\begin{array}{l}\text { Uso de esquemas } \\
\text { simbólicos simples } \\
\text { (sem o modelo) }\end{array}$ & aplica no próprio corpo & $\begin{array}{l}\text { aplica em objetos } \\
\text { figurativos }\end{array}$ & $\begin{array}{c}\text { aplica em objetos não } \\
\text { figurativos }\end{array}$ & Total \\
\hline Diversidade (Peso 2) & $1(x 2 \times 1)=2$ & $2(x 2 \times 2)=8$ & $0(x 2 \times 3)=0$ & $10(8+2+0)$ \\
\hline $\begin{array}{l}\text { Uso de esquemas } \\
\text { simbólicos combinados } \\
\text { (sem o modelo) }\end{array}$ & combina duas ações & $\begin{array}{l}\text { combina três ou mais } \\
\text { ações não ordenadas }\end{array}$ & $\begin{array}{l}\text { combina três ou mais } \\
\text { ações ordenadas }\end{array}$ & Total \\
\hline Diversidade (Peso 3) & $1(x 3 \times 1)=3$ & $0(x 3 \times 2)=0$ & $0(x 3 \times 3)=0$ & $3(3+0+0)$ \\
\hline & & & Total geral & $20(7+10+3)$ \\
\hline
\end{tabular}

Anexo 3. Exemplo do cálculo que deve ser realizado para análise micro referente ao desenvolvimento da linguagem expressiva

\begin{tabular}{|c|c|c|c|c|c|c|c|}
\hline \multicolumn{8}{|c|}{ Pontuação (análise micro) } \\
\hline \multirow{2}{*}{$\begin{array}{l}\text { Indicadores de } \\
\text { desenvolvimento } \\
\text { da linguagem } \\
\text { expressiva }\end{array}$} & \multicolumn{7}{|c|}{ Produções da criança } \\
\hline & Peso 1 & Peso 2 & Peso 3 & Peso 4 & Peso 5 & Peso 6 & \\
\hline $\begin{array}{l}\text { Uso de gestos } \\
\text { dêiticos }\end{array}$ & $\begin{array}{l}\text { por imitação } \\
\text { simples }\end{array}$ & $\begin{array}{c}\text { por imitação } \\
\text { simples } \\
\text { acompanhados } \\
\text { de vocalizações }\end{array}$ & $\begin{array}{l}\text { por imitação } \\
\text { diferida }\end{array}$ & $\begin{array}{c}\text { por imitação } \\
\text { diferida } \\
\text { acompanhados } \\
\text { de vocalizações }\end{array}$ & & & Total \\
\hline $\begin{array}{l}\text { Diversidade } \\
\text { (Peso 1) }\end{array}$ & $3(x 1 \times 1)=3$ & $1(x 1 \times 2)=2$ & $2(x 1 \times 3)=6$ & $2(x 1 \times 4)=8$ & & & $19(3+2+6+8)$ \\
\hline $\begin{array}{l}\text { Uso de gestos } \\
\text { representativos }\end{array}$ & $\begin{array}{l}\text { por imitação } \\
\text { simples }\end{array}$ & $\begin{array}{c}\text { por imitação } \\
\text { simples } \\
\text { acompanhados } \\
\text { de vocalizações }\end{array}$ & $\begin{array}{l}\text { por imitação } \\
\text { diferida ou } \\
\text { representação } \\
\text { simbólica }\end{array}$ & $\begin{array}{l}\text { por imitação } \\
\text { diferida ou } \\
\text { representação } \\
\text { simbólica, } \\
\text { acompanhados } \\
\text { de vocalizações }\end{array}$ & $\begin{array}{c}\text { por imitação } \\
\text { diferida, } \\
\text { acompanhados } \\
\text { de sílabas com } \\
\text { significado ou } \\
\text { onomatopéias } \\
\text { vocais }\end{array}$ & & Total \\
\hline $\begin{array}{l}\text { Diversidade } \\
\text { (Peso 2) }\end{array}$ & $3(x 2 x 1)=6$ & $2(x 2 \times 2)=8$ & $5(x 2 \times 3)=30$ & $2(x 2 x 4)=16$ & $1(x 2 \times 5)=10$ & & $70(6+8+30+16+10)$ \\
\hline $\begin{array}{l}\text { Produção de } \\
\text { verbalizações } \\
\text { acompanhadas } \\
\text { por gestos }\end{array}$ & $\begin{array}{l}\text { sílabas com } \\
\text { significado }\end{array}$ & $\begin{array}{c}\text { palavras } \\
\text { monossilábicas } \\
\text { e/ou interjeições }\end{array}$ & $\begin{array}{c}\text { palavras } \\
\text { onomatopaicas }\end{array}$ & $\begin{array}{c}\text { palavras isoladas } \\
\text { com mais de } \\
\text { uma sílaba }\end{array}$ & $\begin{array}{l}\text { combinação de } \\
\text { duas palavras }\end{array}$ & $\begin{array}{c}\text { combinação de } \\
\text { mais de duas } \\
\text { palavras }\end{array}$ & Total \\
\hline $\begin{array}{l}\text { Diversidade } \\
\text { (Peso 3) }\end{array}$ & $1(x 3 \times 1)=3$ & $2(x 3 \times 2)=12$ & $1(x 3 \times 3)=9$ & $1(x 3 \times 4)=12$ & $1(x 3 \times 5)=15$ & $0(x 3 \times 6)=0$ & $51(3+12+9+12+15)$ \\
\hline $\begin{array}{l}\text { Produção de } \\
\text { verbalizações } \\
\text { Isoladas }\end{array}$ & $\begin{array}{l}\text { sílabas com } \\
\text { significado }\end{array}$ & $\begin{array}{c}\text { palavras } \\
\text { monossilábicas } \\
\text { e/ou interjeições }\end{array}$ & $\begin{array}{c}\text { palavras } \\
\text { onomatopaicas }\end{array}$ & $\begin{array}{c}\text { palavras isoladas } \\
\text { com mais de } \\
\text { uma sílaba }\end{array}$ & $\begin{array}{l}\text { combinação de } \\
\text { duas palavras }\end{array}$ & $\begin{array}{c}\text { combinação de } \\
\text { mais de duas } \\
\text { palavras }\end{array}$ & Total \\
\hline $\begin{array}{c}\text { Diversidade } \\
\text { (Peso 4) }\end{array}$ & $1(x 4 \times 1)=4$ & $2(x 4 \times 2)=16$ & $0(x 4 \times 3)=12$ & $2(x 4 \times 4)=32$ & $1(x 4 \times 5)=20$ & $0(x 4 \times 6)=0$ & $135(4+6+12+32+20)$ \\
\hline & & & & & & Total geral & $275(19+70+51+135)$ \\
\hline
\end{tabular}

